\title{
IRONÍAS, FALACIAS, PERVERSIONES, ENIGMAS: SOBRE EL POSITIVISMO Y LA TESIS DE LA SEPARACIÓN
}

\author{
Luis Manuel Sánchez Fernández \\ Abogado, Master en Gobierno y Politicas Públicas. Profesor de la \\ Unidad de Post Grado en Derecho de la Universidad Nacional de San \\ Agustín, Arequipa, Perú, y de la Academia Nacional de la Magistratura
}

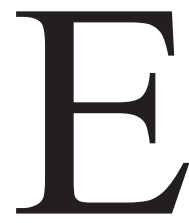

ste ensayo vuelve a ocuparse del positivismo legal y de sus tesis principales. Su interés principal será tratar de señalar algunas dificultades visibles en la exposición positivista, para lo cual se tratará de hacer un recuento de las tesis básicas del positivismo y una crítica justificada de las mismas.

Efectuar ese recuento puede parecer una tarea obvia, pero no lo es de una manera tan simple. Una razón de esto es que las teorías positivistas presentan diferencias notables ya en los trabajos de sus principales representantes. Además los autores positivistas más reconocidos pueden no haber sido muy fieles a sus argumentos, ni han mantenido la misma actitud durante su trayectoria. Adicionalmente, las tesis positivistas han sufrido en sus muchos seguidores significativas variantes y peripecias.

Recordemos que luego de las discusiones Hart-Fuller a fines de los 50, y Hart-Dworkin en los setenta, se ha hablado en el debate anglosajón -virtualmente el escenario de mayor discusión sobre el punto- de "sofpositivismo" (incluso por el propio Hart), positivismo "inclusivo" (Waluchow), positivismo "exclusivo" (Raz), positivismo "sofisticado" (Shiner), positivismo "institucionalista" (MacCormick-Weinberger), positivismo "negativo" o "incorporacionista" (Coleman) positivismo "delgado" (Schauer), positivismo "ético" (Campbell), etc'.

Como ha escrito Ota Weinberger ${ }^{2}$, tratar de mantener a todas estas posiciones dentro de un núcleo de coherencia positivista común, resulta una

${ }^{1}$ Por el lado de los críticos, para marcar las diferencias entre los primeros positivistas y los de generaciones más recientes se ha acuñado expresiones como "paleopositivismo" (Ferrajoli), "post positivismo" (Mazurek, Calsamigilia), etc, para nombrar puntos de vista de los que tenemos noticia.

${ }^{2}$ N. MacCormick, O. Weinberger, An Institutional Theory of Law, D. Reidel Publishing Company, Netherlands, 1986, pp. 115-116. 
tarea difícil. El estudio de Shiner ${ }^{3}$ es también ilustrativo a este respecto, en cuanto a identificar las variantes positivistas principales, lo diferente que es una de otra, e incluso lo contradictorias que pueden ser en puntos claves. Es posible que algunos positivismos no puedan eludir derivar a posiciones de legalismo irremediable o más bien utópico ${ }^{4}$. En otros casos el reconocimiento del punto de vista moral es tan visible que es inevitable preguntarse hasta dónde pueden ser sostenibles tesis como las de la distinción entre punto de vista interno y punto de vista externo, o la separación postulada entre derecho y moral.

Para reconstruir el perfil del positivismo salvando estas contrariedades sin duda una salida legítima es recurrir a los clásicos. Tratar de entender cómo y por qué se definieron a sí mismos como positivistas autores como Bentham, Austin, Kelsen o Hart; si es que lo hicieron, cuándo lo hicieron y cómo lo hicieron.

En una dimensión más importante, este periplo debería ayudar a encontrar lo que es de común a estos autores, y en consecuencia, a reconstruir lo que es consistente como teoría dentro del positivismo, y excluir lo que no lo sea. Creemos razonable pensar que en el punto en que los argumentos de los autores positivistas saltan a consecuencias teóricas que autodestruyen sus presupuestos de partida, tales teorías no deberían ser tenidas estrictamente como positivistas. En esas condiciones, es preferible buscar otros puntos de apoyo para sostenerlas.

\section{Una mirada a los clásicos}

Se acostumbra remitir el positivismo legal hasta Hobbes. Lo que haría a este autor un positivista, según suele decirse, es que hace derivar el derecho de la voluntad (absoluta) del soberano. Y en efecto, Hobbes dice que el "Civil Law es para cada sujeto, aquellas reglas que la Commonwealth ha mandado para él, mediante la palabra, la escritura, u otro signo suficiente de voluntad..." ". La calificación de positivista es por cierto retrospectiva, desde que Hobbes por sí mismo no emplea este vocablo para definir su teo-

${ }^{3}$ Vid. Roger A. Shiner, Norm and Nature, The Movements of Legal Thought, Clarendon Press Oxford, 1992.

${ }^{4}$ Piénsese por ejemplo en el "positivismo ético" del que habla Campbell que aspira a una separación total entre legislación y aplicación del derecho. Según Campbell el positivismo ético "apoya la visión de que la creación y la aplicación de normas deberían mantenerse separadas y que las últimas deben conducirse ajenas a toda valoración libre tanto como sea posible”.T. Campbell, The Point of Legal Positivism, en Legal Positivism, Asgate, Darmouth, England, 1999, p. 337.

${ }^{5}$ Citado por Mark C. Murphy, Was Hobbes a Legal Positivist?, en Legal Positivism, Tom Campbell editor, ed. cit., p. 354. 
ría. Recordemos a propósito que hay otros autores que prefieren calificarlo también como iusnaturalista, entre ellos, Finch ${ }^{6}$, Robles ${ }^{7}$, y más recientemente Murphy ${ }^{8}$.

En Bentham la etiqueta tampoco aparece, pero las tesis que luego Austin, y en particular Hart, asocian con el positivismo analítico se revelan más claras. Bentham habla también del derecho como "mandatos" del soberano", e insiste además en la separación de asuntos "analíticos" y "evaluativos" . "Hay dos caracteres -señala Bentham- uno u otro de los cuales todo hombre que tiene algo que decir sobre la materia del derecho, debe advertirlos; el del expositor, y el del censor. El dominio del expositor corresponde a explicarnos qué es el derecho como el supone; el del censor, observar qué piensa él que el derecho debe ser" ${ }^{\prime \prime}$. Postema ha subrayado que esta distinción benthamiana constituye lo que llama el "dictum positivista"11. En Bentham, anota Hart en la misma dirección, la separación derecho-moral estaría dirigida a evitar el peligro del anarquismo (alguien que pudiera no aceptar el derecho por el hecho de que no es moral); y del reaccionario (alguien que diga este es el derecho por tanto esto es lo que debe ser") ${ }^{12}$.

John Austin parece definirse como positivista ante todo por su reconocimiento de que el único objeto de la filosofía jurídica es el derecho "puesto" por los hombres: "la materia de la jurisprudencia-escribe-, es el derecho positivo: el derecho simple y estrictamente asi llamado: o el derecho puesto por los superiores políticos a los inferiores"13. "El agregado de reglas establecidas por los superiores políticos -dice más adelante-es frecuentemente llamado derecho positivo, o derecho existente por posición" ${ }^{4}$. No es que

\footnotetext{
${ }^{6}$ Vid, John Finch, Introduction to Legal Theory, Sweet \& Maxwell, London, 1979.

${ }^{7}$ G. Robles, Introduccion a la Teoría Del Derecho, Debate, Madrid, 1988, p. 42.

${ }^{8}$ Este autor equipara la teoría de Hobbes con la de Santo Tomas. Vid. C. Murphy, loc. cit, p. 378.

${ }^{9}$ Jeremy Bentham, An Introduction to the Principles of Morals and Legislation, edited by J. H. Burns and H.L.A. Hart, University of London, The Athlone Press, 1970, p. 302.

${ }^{10} \mathrm{~J}$. Bentham, A Fragment on Government, The New Autoritative edition by J. H. Burns and H. L. A. Hart, Cambridge University Press, 1988, p. 7.

${ }^{11}$ Gerald J. Posterma, The Expositor, The Censor, en Legal Positivism, edited by Tom Campbell, ed.cit. p. 412.

${ }^{12}$ H. Hart, The Concept of Law, second edition, Clarendon Press Oxford, 1994, pp. 86-87.

${ }^{13}$ J. Austin, The Province of Jurisprudence Determined, Cambridge University Press, 1995 edited by Wilfrid E. Rumble, p. 18: "the matter of jurisprudence is positive law: law, simply and strictly so called: or law set by political superiors to political inferiors". A lo largo de este ensayo todas las traducciones del inglés son de responsabilidad del autor, salvo que se indique de otro modo.

14 "...the aggregate of the rules established by political superiors, is frequently styled positive law, or law existing by position”, Idem, Lecture I, p. 19.
} 
banalice la existencia de otro "derecho", lo que pasa es que_Austin considera que lo que se llama natural law vendría a ser sólo una porción del derecho positivo y de la moralidad positiva ${ }^{15}$.

En otro lado Austin expone su conocida tesis según la cual las leyes son especies de mandatos (o imperativos): "every law is a command" "I6. "Una ley -dice- es un mandato que obliga a una persona o personas. Pero, a diferencia de un mandato ocasional o particular, una ley es un mandato que obliga generalmente a actuar o a abstenerse, a una persona o personas de una clase" ${ }^{\prime 17}$.

Aunque Austin cree que sólo el soberano puede crear leyes, esto no significa que el derecho positivo consista únicamente en leyes (Estatutes): “... el derecho positivo llamado costumbre (y todo el derecho positivo hecho judicialmente) es establecido por el estado directa o indirectamente, y, por tanto, es imperativo. Estoy lejos de afirmar -indica Austin-que el derecho hecho judicialmente (o en la forma de una legislación impropia) y el derecho hecho por leyes (en la forma de legislación propia), tengan grandes diferencias..." 18 . "(L) eyes positivas -aclara más adelante-, o leyes estrictamente llamadas, son establecidas directa o inmediatamente por tres clases de autores: por monarcas, o cuerpos soberanos, como superiores políticos supremos; por hombres en estado de sujeción, como superiores políticos subordinados; por sujetos, como personas privadas, persiguiendo sus derechos legales. Pero todo el derecho positivo, o todo el derecho estrictamente asi llamado, es un mandato directo o indirecto del monarca o cuerpo soberano en el carácter de superior político..."

Austin es a su vez enfático, o si se prefiere intransingente, en considerar que leyes (positivas) son leyes, independientemente de la bondad o maldad que contengan. "La ciencia de la jurisprudencia (o simple y brevemente,

${ }^{15}$ Idem, p. 115.

${ }^{16}$ Idem. p. 21.

17 " A law is a command which obliges a person or persons. But as contradistinguished or opposed to an ocassional or particular command, a law is a command which obliges a person or persons, and obliges generally to acts or forbearances of a class”. Idem, p. 29.

18 "...the positive law styled customary (and all positive law made judicially) is established by the state directly or circuitously, and, therefore, is imperative. I am far from disputing, that law made judicially (or in the way of improper legislation) and law made by estatute (or in the properly legislative manner) are distinguished by weighty differences... "Idem, p. 36.

19 "Positive laws, or laws strictly so called, are established directly or inmediately by author of three kinds: by monarchs, or sovereign bodies, as supreme political superiore: by men in a state of subjection, as subordinate political superiors: by subjects, as private persons, in pursuance of legal rights. But every positive law, or every law strictly so called, is a direct or circuitous command of a monarch or sovereign number in the character of political superior..." Idem, p. 118. 
jurisprudencia) tiene que ver con el derecho positivo, o con el derecho estrictamente así llamado, caracterizado sin tener en cuenta su bondad o mal$d a d^{\prime 20}$. Sobre la base de lo cual acuña su ampliamente conocida sentencia, que, entendemos ha servido, y sirve de emblema, a los autores positivistas: "la existencia del derecho es una cosa; su mérito o demérito es otra...Un derecho que actualmente existe, es derecho, aunque éste no nos guste o lo desaprobemos ${ }^{\prime 21}$.

Defendiendo a Hobbes, Austin añade luego estas expresiones que lo colocarían sin duda como un "positivista ideológico" en el sentido al que aludía Bobbio en los años sesenta: cuando Hobbes dice que "ningún derecho puede ser injusto", "lo que significa es obviamente esto: que 'ningún derecho positivo es legalmente injusto'. Y su desacreditada proposición, comprendida de este modo, es indisputablemente verdad. Porque el derecho positivo es la medida o test de la justicia e injusticia legal (sic)"22.

Cuando Herbert Hart, el notable ex profesor de Oxford, asume la defensa de la tradición utilitaria de Bentham y Austin, es conciente que estos autores son recusados como positivistas, y desde luego el está dispuesto a aceptar ser ubicado en esa posición, aunque por momentos da la impresión que le cuesta un poco aceptar el mote ${ }^{23}$. Hart defiende especialmente a Austin por haber sido injustamente acusado de "formalista" y de negar la discreción judicial, lo cual no corresponde con lo que éste autor creía ${ }^{24}$.

No es inexacto decir que el principal argumento que Hart asume como positivista es el de la neutralidad de la definición de derecho en relación a las demandas de moralidad, lo que en general se conoce como la tesis de la separación. "El abogado considerará el libro-advierte en el prefacio a The Concept of Law-como un ensayo en jurisprudencia analitica, porque éste está interesado en el esclarecimiento del marco conceptual general del pensamiento legal, más que con la crítica del derecho o la política legal"25. Y más adelante: "Debemos decir aquí que Positivismo Legal significa el

20 "The science of jurisprudence (or simply and briefly, jurisprudence) is concerned with positive laws, or with laws strictly so called, as considered without regard to their goodnes or badness" Idem, p. 112.

21 "The existence of law is one thing; its merit or demerit is another...A law which actually exists, is a law, though we happen to dislike it, or and disapprobation" Idem, p. 157.

22 "His meanings is obviously this: that 'no positive law is legally unjust'. And the decried proposition, as thus understood, is indisputably true. For positive law is the measure or test of legal justice and injustice", idem, p. 217.

${ }^{23}$ Nótese que Hart entrecomilla la palabra "positivismo" para referirse a Austin, The concept of Law, Clarendon Press, Oxford, 1994, p. 8.

${ }^{24}$ Vid. H. Hart, Positivism and The Separation of Law and Morals, en Harvard Law Review, Volume 71, February 1958, Number 4, pp. 608-609.

${ }^{25}$ H. Hart, The Concept of Law, ed. cit. Preface. 
simple argumento de que no es en ningún sentido necesariamente verdadero que las leyes reproducen o satisfacen ciertas demandas de moralidad, aunque en los hechos a menudo hagan eso... "26.

Hart es menos específico que Austin en aducir razones propias a favor de la tesis que asume. Puede pensarse que quizás la da por demostrada, o quiere asumirla como un postulado dogmático. $\mathrm{O}$ quizás considera que es suficiente con reproducir los argumentos de Bentham y Austin como hace tanto en su artículo de 1958 y en su texto fundamental de 1961. Es de notar también que, en otro lado, Hart curiosamente parece hacer suyos argumentos no cognitivos, cuando relata la crítica de Mill a Montesquieu sugiriendo, indirectamente, que los aspectos morales son "prescripciones", y por ello no podrían ser establecidos ni por "observación ni razonamiento"27. Con todo, Waluchow considera que los argumentos de Hart sobre el asunto de la separación serían dos: a) mantener la posibilidad de crítica, para no caer en lo que Bentham llamó la salida anarquista y la salida reaccionaria; b) mantener la claridad intelectual para enfrentar dilemas morales prácticos ${ }^{28} \mathrm{y}$ buscar una respuesta jurídica adecuada a casos difíciles, como el de las Cortes alemanas de 1949, que Hart discute en su referido texto de $1958^{29}$.

El otro argumento explícito que hace al autor inglés llamarse positivista es que postula a su teoría como una teoría descriptiva, preocupada en entender el derecho como un hecho social ("plain facts", como la ha llamado Dworkin) y no de valorarlo. "Una división entre investigaciones interesadas en el análisis del derecho y los conceptos legales, y aquéllos que tienen que ver con la crítica o evaluación del derecho prima facie, parece no sólo posible sino necesaria", escribe ${ }^{30}$. Este punto de vista está presente en toda su obra, aunque quizás queda especialmente claro en el Post script a la segunda edición de The Concept of Law. Hart insiste allá en que su teoría quiere ser "descriptiva", "Una empresa radicalmente diferente -dice- de la concepción de la teoría legal por Dworkin (o 'Jurisprudence' como a menudo (Dworkin) la llama) la cual es evaluativa y justificatoria y vinculada a una cultura particular" ${ }^{\prime 31}$.

26 "Here we shall take Legal Positivism to mean the simple contention that it is in no sense a necessary truth that laws reproduce or satisfy certain demands of morality, though in fact they have often done so... " H. Hart, The Concept of Law, ed.cit., pp. 185-186

${ }^{27}$ Idem, p. 187.

${ }^{28}$ W. J. Waluchow, Inclusive Legal Positivism, Clarendon Press, Oxford, 1994, p. 86-87.

${ }^{29}$ Vid. H. Hart, Positivism and The Separation..., loc. cit. pp. 618-621.

${ }^{30}$ H. Hart, Problems of the Philosophy of Law, en Essays in Jurisprudence and philosophy, Clarendon Press Oxford, 1983, pp. 109-110.

${ }^{31}$ H. Hart, The Concept Of Law, ed. cit, Post script, p. 240. 
Hay que entender también que Hart, implícitamente, defiende la tesis de que sólo es derecho el puesto por los hombres, aunque no lo escriba de ese modo. Cuando Hart habla del origen social de la regla de reconocimiento, y a consecuencia de las fuentes que ésta reconoce ${ }^{32}$, sin duda esta afirmando el carácter humano del derecho, algo que luego ha sido descrito por Raz como la tesis de las "fuentes sociales" 33 .

El positivismo de Hart contiene otros aspectos resaltantes (por ejemplo la distinción entre normas primarias y secundarias) sobre los cuales no es pertinente detenerse aquí. Lo que es llamativo para nuestros fines son sus complicaciones específicas. La principal de ellas, o más bien la complicación general de la teoría de Hart, es que la tesis de la separación se muestra en conflicto con casi todas las nociones que el autor inglés utiliza. Esto ocurre con la diferenciación entre punto de vista interno y externo; con sus tesis iniciales sobre la autoridad-obligación en el derecho; con el concepto de Regla de Reconocimiento; con la tesis de la discreción judicial; y por último, inevitablemente, con el concepto de "contenido mínimo de derecho natural”, según se verá más adelante.

Kelsen, por su lado, parece ser un positivista que se procura tal con mayor convicción. Quizás incluso con demasiada, lo que motiva que Hart le observe que en su Teoría General del Derecho y del Estado podría no haber lugar para una crítica moral del derecho, un "pecado" que - dice Hart- se imputa "indiscriminadamente" a todos los positivistas ${ }^{34}$. Kelsen muestra un interés mayor en encontrar los puntos afines de su teoría con el positivismo analítico ${ }^{35}$, en contraste con la aparente indiferencia de Hart, quién en ningún lado de sus textos claves menciona con particular entusiasmo los trabajos de su predecesor alemán, no obstante que estos son conocidos en inglés cuando menos desde los años cuarenta ${ }^{36}$.

El primer argumento del positivismo de Kelsen sería lo que a veces se llama el punto de vista metodológico, o la idea de un método puramente

32 “... la regla de reconocimiento - escribe Hart- no es pronunciada, sino que su existencia es mostrada en la forma en que reglas particulares son identificadas, sea por las cortes, o los oficiales, o por personas privadas o sus abogados". H. Hart. The Concept of Law, ed. cit. p. 101.

${ }^{33}$ J. Raz, The Authorithy of Law, Clarendon Press Oxford, 1979, p. 38.

${ }^{34}$ H. Hart, Kelsen Visited, en Essays in Jurisprudence and Philosophy, ed.cit., p. 302.

${ }^{35}$ Vid. H. Kelsen, The Pure Theory of Law and Analytical Jurisprudence, en Harvard Law Review, volume 55. Compilado en Mario Jori, Legal Postivism, Darmouth Publishing Company, London, 1992, pp. 44 y ss.

${ }^{36}$ El interés explícito de Hart por los trabajos de Kelsen se expresa en particular en dos ensayos de los años 60: "Kelsen Visited" (1963), y "Kelsen's doctrine of the Unity of the Law" (1968), los cuales, en general no buscan puntos de contacto con la teoría kelseniana, sino puntos de divergencia. 
descriptivo: "Como teoría -escribe Kelsen en la página inicial de su Teoría Pura-su propósito exclusivo es conocer y describir su objeto" ${ }^{37}$. Esta afirmación suena al discurso característico de las ciencias y del positivismo naturalista, al que Hart también adhiere, pero en Kelsen se cruza con alguna suerte de apriorismo neokantiano. En el fondo la "pureza" originaria de la teoría de Kelsen no proviene de su pureza descriptiva; sino de la pureza neokantiana, en el sentido de que el método construye su objeto: siendo el método a priori, el objeto es concebido de ese modo, aislado de antemano en sí mismo. Por ello el mundo del derecho es el de las normas puras que no dependen de otra cosa sino de la norma hipotética fundamental. "La ciencia del derecho-dice Kelsen en el característico y abstruso tono neokantiano- se esfuerza en comprender su objeto 'legalmente', a saber, desde el punto de vista del derecho. Comprender algo legalmente significa comprender algo como derecho, es decir, como una norma legal o como el contenido de una norma legal"38.

El desprendimiento sutil de la pureza neokantiana y su ubicación en una postura positivista más ortodoxa quizás se percibe en los trabajos kelsenianos de los años 40. Por ejemplo, en su Teoría General del Derecho y del Estado el autor está en mejores condiciones para afirmar que "el Derecho Positivo es siempre el derecho de una comunidad", $y$ "desde que el objetivo de la teoría general del derecho es permitir que el jurista interesado en un orden legal particular, el abogado, el juez, el legislador o el profesor, comprender y describir tan exactamente como sea posible, su propio derecho positivo; tal teoría tiene que derivar sus conceptos exclusivamente de los contenidos de las normas legales positivas... lo que no puede encontrarse en los contenidos de las normas legales positivas no puede entrar en un concepto legal'”39. Kelsen se ahorra el circunloquio de recurrir a una supuesta determinación a priori del objeto.

Kelsen también es entonces expreso en sostener que el Derecho, en sentido propio, es el derecho positivo. "El Derecho -si por éste entendemos el derecho positivo, realmente puesto por los hombres y distinto de la moralidad, o de un derecho natural justo o correcto- es esencialmente una norma..." "40. "La teoría pura del Derecho es una teoría del derecho posi-

37 "As a theory, its exclusive purpose is to know and to describe its object" . H. Kelsen, Pure Theory of Law, University of California Press, 1967, p. 1.

38 "The science of law endeavors to comprehend its object "legally", namely from the viewpoint of the law. To comprehend something legally means to comprehend something as law, that is, as legal norm or as the content of a legal norm-as determined by a legal norm", Idem p. 70.

${ }^{39}$ H. Kelsen, General Theory of Law and State, 1945, preface, p. XIII.

40 "Law -whether we mean by this positive law, actually laid down by men, and distinct from morality, or a correct, just, natural law corresponding to morality-is esentially a norm", 
tivo", dice en otro lado ${ }^{41}$. Y caracteriza al derecho positivo como un orden “artificial” de la conducta humana, una "creación" humana ${ }^{42}$.

¿Cuáles son, en concordancia con su teoría, las fuentes del derecho según Kelsen? En esto el jurista de Praga tampoco quiere incurrir en una postura que reduzca el derecho a la ley, aunque en el final puede ser que esto no se logre. "La norma básica -escribe- es luego la "fuente" del derecho. Pero en un sentido amplio cada norma legal es una "fuente" de otra norma, la creación de la cual regula... Cualquier norma legal superior es la "fuente" de la norma legal inferior" 43 . Por tanto, "la constitución es la fuente de los estatutos creados sobre la base de la Constitución; un estatuto es la "fuente" de la decisión judicial basada en éste; la decisión judicial es la "fuente" de los deberes que esta impone sobre las partes..." ${ }^{44}$. De acuerdo con ello serían fuentes el acto judicial, la transacción legal con su forma típica, el contrato, y en otro lugar habla también de la costumbre jurídica ${ }^{45}$.

Por otro lado en la Teoría Pura Kelsen postula la tesis de la separación, sobre tres argumentos principales. El primero sería salvaguardar lo que llama la "pureza del método", en el sentido neokantiano y positivista al que ya nos hemos referido. El argumento que se suma a continuación -aunque no se desprende necesariamente del primero- es que no habría posibilidad de decir qué valores morales integran el Derecho, ya que Kelsen adhiere a un relativismo axiólogico que lo hace suponer la imposibilidad de una descripción de valores universales ${ }^{46}$. El tercer argumento sostiene que si se admite que el Derecho es moral, entonces no habría posibilidad de una crítica moral del mismo ${ }^{47}$. Dice Kelsen, en relación con esto último: "si se asume que el derecho es moral por naturaleza, presuponiendo por tanto un valor absoluto moral, no tiene sentido demandar que el derecho debe ser moral. Este postulado tiene sentido sólo (y la moralidad presupuesta representa

$\mathrm{H}$ Kelsen, The foundation of the Theory of Natural Law, en Essays in Legal and Moral Philosophy, selected by O. Weinberger, D. Reidel Publishing Company, Holland, 1973 p. 114.

${ }^{41}$ Kelsen: The Pure Theory of Law and Analytical Jurisprudence, loc. cit. p. 44.

${ }^{42}$ Vid. The Idea of Natural Law, en Essays in Legal and Moral Philosophy, selected by O. Weinberger, D. Reidel Publishing Company, Holland, 1973, p. 30.

43 "The basic norm is then the "source" of law. But in a wider sense, every legal norm is a "source" of that other norm, the creation of which it regualtes... Any legal superior norm is "source" of inferior legal norm", H. Kelsen, General Theory of Law and State, translated by Anders Wedberg, Russell and Russell, New York, 1945, p. 131.

44 Ibid.

${ }^{45}$ Idem, pp. 134, 136, 140, y 34.

${ }^{46}$ H. Kelsen, Pure Theory of Law, ed.cit., p. 66.

${ }^{47}$ Ibidem. 
un criterio para el derecho) si la posibilidad de la existencia de un derecho inmoral (sic) es admitido..."48

Tampoco el positivismo de Kelsen deja de tener problemas específicos para mantener los dogmas de los que parte. En particular se filtran en la Teoría Pura cuando menos los problemas de la aplicación judicial como creación, y el reconocimiento del elemento volitivo en la interpretación, los cuales favorecen el criterio de una discreción judicial amplia, y con ello se echan dudas sobre la insistencia en la separación entre derecho y moral ${ }^{49}$. Sin embargo, a nuestro juicio, las inconsistencias de Kelsen son lo menos atractivo de su teoría. Kelsen es más interesante por lo que tiene de riguroso (tenemos en mente en particular su teoría de las normas válidas). A diferencia de Hart que resulta más interesante no por la consistencia lograda de su teoría, sino precisamente por lo contrario, por los numerosos puntos de conflicto que contiene y la cantidad de problemas prácticos relevantes que con ello plantea.

\section{El positivismo, del que hablamos}

La escueta recapitulación que se ha hecho de los principales argumentos de los positivistas clásicos, llevaría a apuntar como tesis comunes al positivismo legal las siguientes:

\section{a) Tesis descriptiva, o metodológica: se trata de describir y no valorar el} derecho

Este equivaldría al primero de los tres sentidos de la palabra positivismo de los que habla Bobbio, y al que caracteriza como "modo de aproximarse al derecho" ${ }^{50}$. Si se asume que esto es así, el positivismo jurídico tendría que pasar propiamente como una actitud avalorada o "científica" frente al derecho, a la manera de cualquier actitud científica frente a cualquier objeto de conocimiento. Entonces la tesis no sería específica del positivismo, sino de cualquier corriente científica en general. Sin embargo, lo que la tesis descriptiva positivista postula $-\mathrm{y}$ en la explicación de Bobbio esto no es muy evidente- no pensamos que sea exactamente la aproximación neutral

\footnotetext{
${ }^{48}$ Kelsen, ibid: "if it is assumed that law is moral by nature, then presupposing an absolute moral value, it is meaningless to demand that the law ought to be moral. Such a postulate is meaningful only (and the presupossed morality represents a yardstick for the law only), if the possibility of the existence of an inmoral law is admitted..."

${ }^{49}$ Dejando de lado la tesis de la efectividad como condición de validez, que no logra coherencia con los presupuestos neokantianos que Kelsen acepta y su creencia subsecuente en que del "ser" no puede derivarse un "deber ser".

${ }^{50}$ N. Bobbio, El Problema del Positivismo Jurídico, Distribuciones Fontamara S.A. México D.F. 1995 , p. 42.
} 
al derecho (sin tomar partido por cualesquiera sean los valores que éste tenga); sino la exclusión de los valores del objeto llamado derecho. Cuando los positivistas llevan a la práctica el dictum benthamiano, no parecen estar pensando en describir al derecho como lo encuentren en la realidad, con los valores -y disvalores- que éste tenga (si los tiene); sino que el descriptor metodológicamente no se interesa en tomar en cuenta los valores. El dictum excluye de antemano toda posibilidad de referirse a éstos desde el punto de vista de la ciencia del Derecho, aun cuando el objeto pudiera implicarlos.

Kelsen, como se vio, hace esto por los argumentos del apriorismo kantiano, el relativismo moral y la imposibilidad crítica. Hart, según parece por que quiere ser consecuente con la disyuntiva austiniana de que una cosa es conocer y otra valorar, y quizás piensa que los valores no se pueden conocer. O porque -interesado únicamente en el Derecho como un hecho social-parece presuponer que los morales no son hechos sociales, o que no es un hecho que aspectos morales integran el derecho. Uno podría pensar que los positivistas, en especial los de la corriente de Hart, parecen creer que un hecho social (fact) es tal sólo cuando es observable o visible (más o menos al modo de los realistas escandinavos), o cuando puede ser contrastable con algún patrón exterior verificable (digamos, conductas y reglas manifiestas $\left.{ }^{51}\right)$. Y desde que la moral -o los aspectos valorativos del derecho, si los tuviera- no parecen ser verificables con nada, no constituirían por consiguiente facts $^{52}$.

Lo específico de la tesis descriptiva positivista legal viene a ser, entonces, un aspecto que ya fue observado en el positivismo como epistemología general. La descripción del objeto es asumida de un modo naturalista. Digámoslo en bruto: sólo lo que se puede medir u observar es un hecho. Lo que no tiene patrón de comparación no lo es. Esto tendría que ocurrir con los aspectos valorativos del derecho. Alguien podría sentir aquí un cierto sabor a positivismo lógico, pero no hay pruebas de que Hart, ni Kelsen adscriban concientemente a ese punto de vista.

Adicionalmente, desde el punto de vista de quién describe, el conocimiento de los hechos que conforman el derecho es asumido por los positivistas como si el sujeto -y con él toda su superestructura de valores- no tuviera ningún tipo de influencia sobre lo que se quiere describir. Las definiciones jurídicas de los positivistas no performarían en nada la realidad del derecho. Se pretenden pragmáticamente neutrales. Se cava así un abismo insalvable entre sujeto y objeto de conocimiento, más o menos a la manera en que Hart

\footnotetext{
${ }^{51}$ Vid. H. Hart, The Concept of Law, ed. cit, p. 89.

${ }^{52}$ Cfr. por ejemplo Raz, The autorithy of the Law, ed. cit., p. 42.
} 
se imagina que son posibles un punto de vista interno y otro externo sobre el derecho, presuntamente ambos con la misma validez descriptiva.

Entonces, la motivación "científica" es entendida por el positivismo casi como "ceguera" a los aspectos valorativos. Y la tesis positivista correctamente planteada no resulta "descriptiva" a secas, sino "descriptiva de no-valores". En definitiva el positivismo no acepta que los valores sean describibles y por lo tanto deben excluirse del objeto llamado "Derecho" y de la ciencia que lo estudia. De manera que si alguien quiere llamarse positivista porque le interesa una neutralidad "científica" e imparcial en el estudio de todos los aspectos del derecho, seguramente cometería un error.

\section{b) Tesis del derecho "puesto", o de las "fuentes sociales" (Raz) o tesis "social" (Coleman)}

El único derecho existente es el derecho puesto por los seres humanos ${ }^{53}$, el cual se puede verificar por la conducta de la gente y de los oficiales.

Esta tesis no se sigue de la tesis descriptiva de no-valores, pero es compatible con ella, al menos parcialmente. Además esta sí es una tesis específica del positivismo, y concretamente -como se sabe- es la que permite diferenciar al positivismo del iusnaturalismo. Tanto en Austin, Kelsen y Hart, este punto de vista es defendido sin mayores matices de diferencia.

\section{c) Tesis de la separación: el derecho es separable de la moral}

Tesis que debe considerarse también como específica del positivismo, aunque se discute bastante acerca de en qué nivel es constatable esa separación $^{54}$ : si a nivel factual necesario, a nivel factual contingente o a nivel conceptual. Como se vió antes, la tesis es común y es defendida por Bentham, Austin, Hart y Kelsen, aunque las razones en cada caso no son exactamente las mismas. No es, además, una tesis que se desprenda necesariamente de a) ni de b), y bajo ciertas condiciones podría ser, más bien, incompatible con ambas. El que haya que describir el derecho no significa que haya que dejar de lado sus aspectos valorativos. Y el que el derecho sea obra humana no quiere decir de por sí que sea obra amoral u obra separada de la moral. Lo contrario tendría que ser más verdadero; salvo que se asuma que las sociedades construyen instituciones sin ninguna finalidad, o con alguna intención maléfica.

\footnotetext{
${ }^{53}$ Idem, p. 38. En opinión de Raz ésta sería la tesis positivista fundamental, a la que se debe precisamente el nombre de "positivismo".

${ }^{54}$ Vid, Klaus Füber, Farewell to Legal Positivism, en The Autonomy of the Law, edited by Rober P. George, Clarendon Press Oxford, 1996.
} 


\section{d) Tesis de la discreción judicial}

El reconocimiento de la discreción judicial está presente tanto en Kelsen, como en Hart. En el primero de modo declarado cuando postula el cáracter creador de la aplicación e interpretación del derecho. En el segundo quizás más bien de modo reticente. Hart habla de discreción "intersticial" y, aunque acepta que hay penumbra en el lenguaje del derecho, sostiene que las "elecciones en la penumbra" se dan dentro de las "líneas" que controlan las decisiones de las cortes ${ }^{55}$. Este criterio resulta compatible con la tesis de las fuentes sociales, aunque no derivable directamente de ella. En cambio no es una conclusión que se desprenda de la tesis de la separación, y tampoco es compatible con ésta. Por el contrario es una tesis que tiene potencial contradictorio y destructivo dentro de la teoría positivista, en tanto deja abierto el campo para el ingreso de los valores, a través de las decisiones de los jueces.

Esta observación afecta sobre todo a Kelsen. Al profesor austriaco parece no haberle preocupado mucho eso, y su "dinámica" jurídica es apta a reconocer los espacios de creación libre por el juez. En cambio para Hart fue un permanente dolor de cabeza, como de algún modo lo fueron también sus otras tesis; conflictos que Hart intentó resolver, finalmente, por alguna forma de positivismo inclusivo que él acepta al precio de poner en tela de juicio, en forma velada, al dogma de la separación. Pensamos que aunque algunos positivistas defienden la tesis de la discreción ${ }^{56}$, el positivismo como teoría no tiene aptitud para sostener ello.

\section{e) Tesis del derecho estatal}

Este criterio lo usa Bobbio para caracterizar al positivismo en tanto "teoría" (el segundo modo de entender el positivismo según el ilustre profesor italiano ${ }^{57}$ ) y supone que el derecho sería ante todo derecho estatal. Un punto de vista semejante, no parece haber sido suscrito especialmente por todos los positivistas. Al menos no por Hart, y por Kelsen quizás sólo en tanto habla del estado en un sentido amplio, aunque puede estimarse que late implícito en las teorías de ambos. Bobbio tiene, sin embargo, razón en que

${ }^{55} \mathrm{El}$ texto literal de lo que dice Hart es el siguiente: “...to insist on the utilitarian distinction is to emphasize that the hard core of settled meaning is law in some centrally important sense and that even if there are borderlines, there must first be lines(sic). If this were not so the notion of rules controlling courts' decisions would be senseless as some of the realists...claimed" H. Hart, Positivism and the separation of Law and Morals, loc. cit. p. 614.

${ }^{56}$ Cfr. L. Prieto Sanchís, Constitucionalismo y positivismo, Fontamara S.A., México D.F., p. 14.

${ }^{57}$ Vid. N. Bobbio, op. cit., p. 43 y ss. 
finalmente, a la luz de los hechos, en las sociedades actuales el positivismo ha devenido en la teoría (ideología) del derecho estatal. Ha apuntalado el monopolio de la producción del derecho por el estado-aparato, vía a través de la cual el paso al legalismo como ideología es casi imperceptible, aunque Bobbio no cree que haya conexión entre ambos extremos ${ }^{58}$. En cualquier caso, se trataría de una tesis sociológica, y no pensamos que pueda usarse para caracterizar al positivismo en tanto teoría jurídica.

\section{f) Tesis del derecho como organización de la fuerza.}

En Kelsen esta tesis se halla presente, quizás incluso en Hobbes ${ }^{59}$. En Hart esto no es tan exacto, ni siquiera en el sentido de afirmar el carácter coactivo como definitorio del derecho, desde que Hart parece pensar que las sanciones gozan de una condición semejante a la que tendría la moral en el Derecho, y no termina de aclarar si esa vinculación es necesaria y con qué intensidad lo es ${ }^{60}$. Podría ser un planteamiento compatible con la tesis social, y quizás con la tesis de la separación (siempre que se asuma que el derecho es una organización amoral de la fuerza). En cualquier caso ninguno de los autores positivistas lo plantea de ese modo. La reflexión sobre el derecho positivo como organización de la fuerza no constituye un punto de referencia central de la obra hartiana, y finalmente tampoco de Kelsen, más allá de las reflexiones generales que se contienen en la obra de este autor ${ }^{61}$. La tesis así planteada parece más propia de la tradición marxista, y por ello pensamos que no se vincula a las tesis positivistas básicas, ni es una consecuencia necesaria de ellas.

Resumiendo todo lo dicho, es posible sostener que las tesis centrales y definitorias del positivismo jurídico como tal son tres: 1) la tesis descriptiva de no-valores ${ }^{62}$, 2) la tesis de las fuentes sociales, y 3) la Tesis de la separación. El resto de afirmaciones comentadas pueden ponerse en el margen,

${ }^{58}$ Cfr. Idem, p. 40.

59 "Positive law is essentially an order of coercion..." dice Kelsen, Natural Law Doctrine and Legal Positivism. En General Theory of Law and State, ed.cit., Appendix, p. 392.

60 "The connection between law and moral standards and principles of justice is therefore as little arbitrary and as "necessary" as the connection between law and sanctions, and the pursuit of the question whether this neccesity is logical (part of the "meaning" of the law) or merely factual or causal can safely be left as an innocent pastime for philosophers", H. Hart, Positivism and Separation..., loc. cit. p. 622.

${ }^{61}$ Cfr. Oscar Córreas, Critica de la Ideología Jurídica, UNAM, 1993, p. 54.

${ }^{62}$ Desde la pretensión positivista ésta tendría que ser la tesis de la descripción en el sentido de neutralidad a los valores (el jurista no toma partida por ningún valor). Sin embargo, de la manera en que la entienden, según se dijo antes, la tesis equivale más bien a no describir valores (que es algo distinto a no tomar partido por alguno de ellos), y por ello preferimos denominarla como tesis descriptiva de no-valores. 
sea porque los positivistas clásicos no las postulan distintivamente (caso de la tesis del derecho estatal), porque no son puntos de vista originales del positivismo (tesis metodológico científica, y tesis del derecho como organización de la fuerza), o porque son claramente incompatibles con los dogmas de partida (tesis de la discreción ${ }^{63}$ ).

Con ligeras variantes (sobre todo en relación a la formulación de la primera), estas tres tesis configuran la imagen de positivismo que se acepta generalmente entre los autores. Coleman y Leiter, por ejemplo, sostienen que todos los positivistas comparten la "tesis social" y la tesis de la "separabilidad"64. Raz habla por su lado de la tesis "reductivo semántica", de la "conexión contingente" derecho moral, y de la tesis de las "fuentes" ". Y Calsamiglia ha afirmado más recientemente que "el positivismo conceptual se asocia con dos tesis importantes. En primer lugar la defensa de la teoría de las fuentes sociales del derecho, y en segundo lugar, la tesis de la separación entre el derecho, la moral y la política" $"$.

Hart, en una nota a pie de página a su ensayo de 1958, sugiere también que estos tres serían los argumentos de mayor consenso entre los positivistas. Hay cinco significados asociados con el positivismo, escribe: a) leyes como mandatos de los seres humanos; b) la no conexión necesaria entre derecho y moral; c) la afirmación de que el estudio de los conceptos legales es valioso en sí mismo y es diferente de las investigaciones históricas o sociológicas, así como de la apreciación del derecho en términos morales, sociales o de otra clase (en otros términos, el derecho tiene objeto propio, y describir es diferente a valorar); d) el argumento de que el derecho es un sistema lógico cerrado; e) el argumento de que los juicios morales no pueden ser establecidos por medios $\operatorname{cognitivos}{ }^{67}$. De esos cinco significados, Hart sostiene que Bentham y Austin (y hay que entender que, por consiguiente,

${ }^{63}$ Lo contrario sería optar por la tesis de la discreción y descartar la tesis de la separación. Pero esta opción, aparte de que no corresponde al orden histórico de fundamentación, resultaría menos positivista que la que optamos.

${ }^{64}$ J. Coleman, B. Leiter, Legal Positivism, en A Companion to philosophy of Law, edited by Dennis Paterson, Blackwell Publishers, Great Britain, 1999, p. 241.

${ }^{65}$ J. Raz, The Purity of The Pure Theory, en Mario Jori, Legal Positivism, ed. cit., p. 81. Sin embargo, como el propio Raz dice, la tesis "reductivo semántica"(en el sentido de que los enunciados del derecho no serían normativos sino descriptivos), no es aceptada por Kelsen, p. 82.

${ }^{66}$ A. Calsamiglia, Postpositivismo, en DOXA, 21-I, (Edición virtual), Alicante, 1998, p. 210. Véase también, Luis Prieto Sanchís, Constitucionalismo y Positivismo, Distribuciones Fontamara, México D.F., 1997, p. 13. Y Tom Campbell, quién mantiene que son tres las tesis claves del positivismo: la tesis de la separación, la de los orígenes históricos e institucionales de las leyes (tesis social), y la del lugar central de las reglas en el sistema, Legal Positivism, ed. cit. Introduction.

${ }^{67}$ H. Hart, Positivism and The Separation..., loc.cit, pp. 601-602. 
él también) aceptan los tres primeros ${ }^{68}$, pero no los restantes. Por otro lado descarta enfáticamente que algún jurista analítico haya defendido la tesis del orden lógico cerrado ${ }^{69}$.

Ahora bien, de las tres tesis que asumimos como comunes y definitorias del positivismo, la primera (la tesis descriptiva) es entendida de un modo parcialmente descriptiva por los positivistas, como ya se dijo, lo que equivale a decir que la tesis es inconsecuentemente desplegada en la práctica, desde que los positivistas se niegan a describir (aunque sea neutralmente) los aspectos valorativos que -en los hechos- el derecho incorpora.

La segunda, la tesis de las fuentes sociales, es una afirmación evidente. Se podría decir incluso que ahora es una verdad de perogrullo, en el sentido de que, en la práctica, el derecho no es reconocible como tal, al margen de una decisión humana autorizada. Lo que no quiere decir, por cierto, que las razones para constituir el derecho sean meramente convencionales, o dependan del arbitrio del agente. Creemos justificado pensar que esta es la gran conquista del positivismo jurídico, su tesis principal como indica Raz, y además -adelantando la conclusión que surgirá de los párrafos que continúan- su única tesis exitosa.

La tercera tesis, la más defendida por los positivistas, la de la separación entre derecho y moral, presenta en verdad muchos problemas. Se diría que demasiados, lo que pensamos puede evidenciarse mejor de las discusiones que prosiguen.

\section{Ironías}

\section{El derecho que "es"}

Hart insiste en que el derecho sólo puede estudiarse como un hecho social (fact). Pero al parecer las orientaciones sustantivo-valotarivas (de diferente grado, tipo, o significado) que han formado y forman parte de todos los órdenes jurídicos (no hay orden jurídico sin alguna sustancia), no serían un fact. ¿Por qué descriptivamente la teoría no habría de dar cuenta de las valoraciones que "de hecho" el derecho tiene? Se podría responder que el aspecto valorativo -si bien está unido al derecho- convencionalmente es mejor dejarlo fuera del objeto de estudio llamado derecho, como los positivistas hacen, pero ésa no es la única alternativa. Se podría proponer también lo contrario: la necesidad de incluir los valores en el objeto de estudio, desde que el argumento positivista fracciona bruscamente aspectos de un hecho ("forma"

\footnotetext{
${ }^{68}$ La tesis c) puede verse en la exposición de Hart, como otro modo de expresar lo que aquí hemos llamado la "tesis descriptiva de no-valores".

${ }^{69}$ Ibidem.
} 
y “contenido") que algunos considerarían indisoluble; lo que, además, podría no ser lo más conveniente para los fines de una buena convivencia reglada.

Partiendo de la circunstancia verificable de que el derecho no opera en ningún caso sin algún referente sustantivo, se podría decir también, en otra opción, algo como "Muy bien, el derecho está unido a valores, pero no consiste distintivamente en valores, sino en compulsoriedad". O en otra alternativa: "Muy bien, el derecho está unido a valores, pero no a un valor en particular, sino a algún valor que valga para cada comunidad" (como parecía pensar Recaséns Siches, por ejemplo), o "está unido a múltiples valores", etc. De la circunstancia de que puedan haber muchos valores conectados en el derecho, no resulta inevitable que se tenga que dar el salto contraintuitivo a sostener que el objeto derecho es separable de toda valoración.

Pero, por otro lado, ¿qué es, concretamente, el derecho positivo más allá de decir que es el "derecho puesto por los hombres"? Todos los clásicos, según se vió, son abiertos a reconocer que en última instancia derecho no es únicamente el contenido en las leyes; sino también el que proviene de las decisiones judiciales, y aun de la costumbre jurídica. Sin duda es por ello que tanto la costumbre como la judicatura son admitidas como "fuentes" del derecho. Pero si esto es así, la exclusión de los valores se debilita. Tengamos en cuenta que las costumbres jurídicas existen fuertemente dependientes de las valoraciones reiteradas que se practican en una comunidad, y cuando se reconocen como derecho, esto ocurre precisamente por su contenido. Además las decisiones judiciales son fuente no sólo cuando son isomórficas (en el sentido de Wróblewsky) sino también -y sobre todo- cuando son creativas. Y son creativas cuando apelan a valoraciones no explícitas en el sistema normativo pre-constituido. Lo jurídico no puede constituirse sin alguna referencia sustantiva.

En otros términos, sostener que el derecho es lo que dicen sus fuentes, no excluye que las fuentes operen con valores. Para afirmar que el derecho no implica valor alguno (moral, político, o del tipo que fuese), primero habría que demostrar que no hay valores en las fuentes sociales: ni en la ley, ni en la costumbre, ni en las decisiones de los jueces. Y esto es algo que los positivistas no han hecho, y que parece implausible que pueda hacerse.

Füber ha hecho notar también, por otro lado, que al sostener que la definición del derecho no requiere de referente sustantivo alguno, el descriptivismo positivista incurre paradójicamente en convencionalismo, de acuerdo con él cual cualquier cosa que estipulen las fuentes podría ser derecho ${ }^{70}$.

${ }^{70}$ Vid. Klaus Füber, Farewell to 'Legal Positivism': The Separation Thesis Unravelling, en The Autonomy of the Law, edited by Robert P. George, Clarendon Press Oxford, 1996, pp. 126-127. 
El concepto de derecho no requeriría de referente sustantivo identificable, algo que, además, otros autores (iusnaturalistas) consideran imposible de sostener a partir del análisis de conceptos jurídicos usuales como "malicia", "contrato válido", "igual trato", "debido proceso", etc. ${ }^{71}$

\section{La Separación}

La primera complicación de la tesis hartiana de la separación fuerte derecho- moral $^{72}$ (separación descriptiva) proviene de que ésta se vé afectada por la distinción entre punto de vista interno y punto de vista externo. "Cuando un grupo social -dice Hart- tiene ciertas reglas de conducta, este hecho ofrece una oportunidad para varias clases de afirmaciones estrechamente relacionadas. Es posible interesarse en las reglas, sea simplemente como un observador que no acepta para sí mismo aquéllas, o como un miembro del grupo que acepta y usa las reglas como guía de conducta. Podemos llamar a estos el punto de vista "externo" e "interno", respectivamente"

Claramente el reconocer que desde el punto de vista interno el derecho opera como "guía de conducta" por que es "aceptado" por los participantes, implica reconocer que contiene algún punto de vista valorativo. De otro modo es poco probable que los participantes encontrarían justificado asumirlo como "guía" 74 . Eso quiere decir que, cuando menos desde el punto de vista interno, la tesis de la separación no se sostiene incólume; de tal modo que se podría pensar que el ocaso de la tesis positivista de la separación comienza precisamente en el punto de vista interno ${ }^{75}$.

El profesor tampoco explica por qué considera que el punto de vista externo es tan legítimo o aceptable en la misma jerarquía que el punto de vista

\footnotetext{
${ }^{71}$ Cfr. Brian Bix, Natural Law Theory, en A Companion to Philosophy of Law and Legal Theory, Blackwell Publishers, 1999, UK, p. 238.

${ }^{72}$ Hay que destacar que estas dificultades se le presentan a Hart por su preocupación en acercarse mejor al derecho socialmente existente. Kelsen, en cambio, no parece muy interesado en esto, y se contenta con definir las normas, la norma fundamental, la validez, y la autoridad de modo formal. Y cuando postula la tesis de la libre creación judicial se desentiende de cualquier consecuencia teórica que ello pudiera acarrear.

73 "When a social group has a certain rules of conduct, this fact affords an opportunity for many closely related yet different kinds of assertion; it is possible to be concerned with the rules, either merely as an observer who does not himself accept them, or as a member of the group which accepts and uses them as guides to conduct. We may call these respectively the "external" and the "internal" points of view. Statements made from the external point of view may themselves be of different kinds ...", H. Hart, The Concept of Law, ed.cit., p. 89.

${ }^{74}$ En el mismo sentido, Sebastián Urbina, Reason, Democracy, Society, Kluwer Academic Publisher, Netherlands, 199, p. 57. Cfr. También, L. Prieto S., op. cit. pp. 53 y ss.; F. Laporta, Entre el Derecho y la Moral, Distribuciones Fontamara S.A., México D.F., 1995, pp. 37 y ss.

${ }^{75}$ Véase también, Goldsworhty, The Self-Destruction of Legal Positivism, en Oxford Journal of Legal Studies, Volume 10, Oxford University Press, 1990, p. 452.
} 
interno para entender el derecho ${ }^{76}$, y por qué al final, en el contexto de su obra, privilegia el punto de vista externo -y no el de los participantes- para definir o "elucidar" el derecho, como él dice.

\section{La autoridad del derecho}

La segunda complicación hartiana proviene de la tesis sobre la autoridad y la obligación de obedecer el derecho. En su teoría existe una ambigüedad crucial que ya ha sido evidenciada por otros autores ${ }^{77}$. Hart parte de marcar diferencia con los imperativos austinianos, señalando que la autoridad del derecho no puede provenir de la voluntad de quién manda. La autoridad del derecho depende de su aceptación ${ }^{78}$, y concretamente, de su aceptación desde el punto de vista interno, al menos por los operadores del derecho, si no por los ciudadanos ${ }^{79}$. Esto define precisamente el contenido normativo del derecho, que, de otro modo se reduciría a pura voluntad psicológica, o a un mandato. Entonces, la autoridad presupone también algún tipo de reconocimiento valorativo $-\mathrm{y}$, hay que decir, moral en algún sentido- por los participantes.

Hart trata de eludir estas consecuencias de su razonamiento, recurriendo al argumento de que la aceptación puede fundarse en otras consideraciones: "cálculos de interés de largo plazo", "interés desinteresado en los demás", "imitación irreflexiva de conductas tradicionales", o "el simple deseo de hacer lo que hacen otros" $"$. Pero entonces surge la duda si con esto Hart no está confundiendo los motivos de un individuo para comportarse de una cierta manera, con los motivos para aceptar la autoridad del derecho en cuanto tal. Como dice Raz "uno no puede aducir las preferencias de uno, o el auto interés de uno, por sí mismos, como justificación para sostener que las otras personas deben, o tienen un deber de actuar en una cierta manera. Reclamar que otro tiene que actuar en mi interés es normalmente hacer un

\footnotetext{
${ }^{76}$ Que el externo no es un punto de vista tan legítimo ni tan acertado -en tanto no toma en cuenta las razones valorativas de los participantes- se evidencia cuando los autores positivistas -Raz en primer término, y luego Hart y MacCormick-, sugieren que se necesita un tercer punto de vista, que sería el de aquél que - por propósitos "heurísticos"- adopta el punto de vista interno pero sin un compromiso genuino con éste. Ver Goldsworhty, loc. cit. p. 450.

${ }^{77}$ Véase por ejemplo, Francisco Laporta, Entre el Derecho y la Moral, ed. cit. 37-38. S. Urbina, op. cit. p. 34.

78 "... it is true that the coercive power of law presupposes its accepted autorithy.", $\mathrm{H}$. Hart, The concept of Law, ed. cit., p. 203.

${ }^{79}$ Vid. Jeffrey Goldsworhty, loc. cit., p. 450. También Michael Bayles, quién indica que la Regla de Reconocimiento hartiana dependería: a) de la obediencia general de los ciudadanos, b) aceptación por los oficiales (por motivos de respeto), Hart's Legal Philosophy, An Examination, Kluwer, Netherlands, 1992, pp. 72-73).

${ }^{80}$ Citado por Goldsworthy, loc. cit. p. 454.
} 
reclamo moral acerca de sus obligaciones morales" $"$. En otras palabras, la autoridad (y el deber de obediencia) del derecho no pueden lograr aceptación universal sobre la base del auto-interés. Motivaciones utilitarias (no morales) no logran servir de base para exigir obediencia general al derecho, lo que no impide que el individuo pueda comportarse de maneras utilitarias en su vida privada.

Los seguidores de Hart han tratado de salvar esta dificultad de diversas maneras. Raz escoge la vía de separar "autoridad" de "aceptación moral", y sostiene que la primera proviene de la función de coordinación de la vida social que el derecho cumple ${ }^{82}$, en tanto que la segunda operaría en el plano interno. De este modo se tendría una situación en la que los participantes serían capaces de aceptar moralmente reglas sin contenido moral ${ }^{83}$. Coleman y Leiter sugieren que hay que distinguir dos autoridades: la de la Regla de Reconocimiento, que no proviene del punto de vista interno sino de la existencia de "conductas convergentes", y la de las reglas subordinadas a ésta cuya autoridad dependería de ser originadas en una fuente ${ }^{84}$. Schauer al observar que todo esto es, ciertamente, problemático para el positivismo, prefiere pensar que no hay un problema de autoridad para dar una respuesta positivista al concepto de Derecho. “... algo puede ser derecho y no tener autoridad" escribe ${ }^{85}$. Schauer "adelgaza" el positivismo para mantener su teoría indemne de moral, de manera análoga a cuando Raz se da cuenta que el positivismo no satisface las necesidades del razonamiento legal ("adjudicación”), prefiere creer que los problemas de la adjudicación no conciernen a la teoría del derecho ${ }^{86}$.

\section{La Regla de Reconocimiento}

La tercera complicación proviene de la Regla de Reconocimiento. Se ha dicho que el concepto de Regla de Reconocimiento (RR) es más afortunado que el de norma fundamental en Kelsen, porque significa una aproximación social y no apriorística al derecho. Y esto puede tenerse como cierto; aunque, por otro lado, siempre resulta difícil distinguir en qué consiste la regla de reconocimiento y en qué consisten las fuentes del derecho.

${ }^{81}$ Citado por Goldsworthy, Idem, p. 455.

${ }^{82}$ Idem, p. 461.

${ }^{83}$ Idem, p. 463.

${ }^{84}$ J. Coleman, B. Leiter, op. cit, pp. 253, 258.

${ }^{85}$ Frederick Schauer, Positivism Trough Thick and Thin, en Legal Positivism, Tom Campbell editor, ed. cit, p. 72.

${ }^{86}$ Vid. Goldsworhty, loc. cit. pp. 474-475. 
Tampoco RR constituye de por sí una fórmula que excluya referencias morales. Esto es latente ya en la primera edición del texto clásico de Hart: "Dondequiera que una regla de reconocimiento sea aceptada, ciudadanos y oficiales de justicia son provistos con un criterio autoritativo para identificar las reglas primarias de obligación. El criterio previsto puede-como se ha visto-tomar una o más variedades de formas: éstas incluyen referencia a un texto autoritativo, disposiciones legislativas, costumbres prácticas; hasta declaraciones general de personas especificadas, o decisiones judiciales pasadas en casos particulares..." ${ }^{" 87}$. Ya antes se ha dicho que fuentes como la costumbre, las decisiones judiciales, o incluso las decisiones legislativas no excluyen presupuestos morales, y de acuerdo con Hart, nada impediría que esta moralidad sea reconocida como derecho por alguna regla de reconocimiento.

En la segunda edición de The Concept of Law, esta conclusión se explicita de mejor modo: “...la regla de reconocimiento puede incorporar como criterio de validez legal, conformidad con los principios morales o valores sustantivos; mi doctrina es lo que se ha llamado "soft positivism" Éste es un punto de vista común al llamado "positivismo inclusivo" (que según Waluchow sería compatible además de Hart, con Austin y Bentam) y al "incorporacionismo" de Coleman. Según este último autor "la regla de reconocimiento en una particular comunidad acepta, en efecto, que ciertas normas son derecho siempre que ellos satisfagan las demandas de justicia, o que ellas no pueden ser derecho..." $"$. Y según Waluchow, el positivismo legal inclusivo acepta que "principios y valores morales cuenten entre los posibles fundamentos que un sistema legal puede aceptar para determinar la existencia y contenido de las leyes válidas. Como ejemplo, uno puede considerar la posibilidad de que una regla de reconocimiento de un sistema legal, podría contener explícitamente un test o criterio moral (énfasis nuestro) para la validez legal de la legislación parlamentaria o del congreso. Si es posible para la regla de reconocimiento contener tal criterio, luego la

87 "Wherever such a rule of recognition is accepted, both private persons and officials are provided with authoritative criteria for identifying primary rules of obligation. The criteria so provided may, as we have seen, take any or more of variety of forms: these include reference to an authoritative text; to legislative enactment; to customary practice; to general declarations of especified persons, or to past judicial decisions in particular cases.. " $\mathrm{H}$. Hart, The Concept of Law, ed.cit., p. 100.

88 “... the rule of recognition may incorporate as criteria of legal validity conformity with moral principles or substantive values; so my doctrine is what has been called 'soft positivism'", Idem, p. 250.

${ }^{89}$ J. Coleman, B. Leiter, loc. cit. p. 251. 
validez del derecho puede en algunas ocasiones no ser determinada sólo por su pedigree, es decir por la manera de su adopción" $"$.

Pero entonces ¿por qué decir a priori que el derecho es separable de cualquier valor? El positivismo no tendría por qué afirmar la separación desde el comienzo. Desde el punto de vista positivista, más exacto sería decir algo como: "el derecho es un sistema de reglas válidas cuyo contenido -moral o no- depende de la regla de reconocimiento". RR se amplía tanto que finalmente derecho puede ser cualquier norma socialmente aceptada como tal (si ello es posible). "En el extremo -dice por otro lado Schauer- ... un sistema legal con una sola norma legislativa promulgada -"sé moral"-contaría como un sistema legal positivo tan luego como el reconocimiento de esta norma como norma legal, no requiere recurrir a criterios morales" ${ }^{\prime 1}$. En otros términos: el derecho es, lo que la regla de reconocimiento dice que es.

Uno se pregunta si todo esto no equivale a la tautológica afirmación de que "es derecho cualquier norma que la sociedad reconoce como tal". Después de lo cual la tarea para esclarecer qué sea derecho sigue por supuesto pendiente. RR no tiene contenidos específicos de reconocimiento. RR podría contener criterios técnicos, morales, políticos, inicuos, u otros. ¿Qué es, entonces, la Regla de Reconocimiento? ¿Es realmente algo distinto a una entelequia?

Si se aceptan los criterios inclusivos, y el Derecho puede ser cualquier compulsión reconocida por la regla de reconocimiento, Hart no tendría cómo refutar a Austin ¿Por qué no podrían ser derecho los imperativos? Por el ejemplo de los bandidos, podría responderse ¿Y el ejemplo de las dictaduras? ¿Por qué éstas sí tendrían que ser derecho? Y desde luego la teoría de Hart tampoco tendría que descartar que el Derecho fuese moral, porque podría llegar un momento en que lo moral, o lo sustantivo, fuese lo intrínsecamente distintivo del Derecho, de acuerdo con la regla de reconocimiento de algún lugar, ¿como el Irán de Khomeini por ejemplo?

Lo que es más claro es que a estas alturas ya nos hallamos bastante lejos de la tesis de la separación. Llevada a sus últimas consecuencias la tesis de

90 "Which we have called inclusive legal postivism, moral values and principles count among the possible grounds that a legal system might accept for determining the existence and content of valid laws. As an example, one might consider the possibility that a legal system's rule(s) of recognition could contain explicitly moral test or criteria for the legal validity of Congressional or Parliamentary Legislation. If it is possible for the rule of recognition to contain such criteria, then a law's validity might on some ocassion not be determined by its pedigree alone, that is, by the fact and manner of its adoption", W.J. Waluchow, Inclusive Legal Positivism, ed. cit., p. 82.

${ }^{91}$ F. Schauer, loc. cit., p. 194. El autor no llega a interrogarse qué pasa si la única norma promulgada fuese "sé inmoral": ¿RR (es decir, los operadores del derecho) reconocerían a ésta como norma legal? 
la Regla de Reconocimiento, por Hart y los inclusivos, autodestruye cuando menos la tesis de la separación. Y por ello, no ha de faltarle razón a Dworkin cuando considera que operaciones como las que practican los inclusivos son ilegítimas, y sin duda, autodestructivas, en el marco del positivismo y su dogma fundamental. No es que sean indeseables, todo lo contrario. Podría aceptarse que son un paso adelante en el entendimiento de lo jurídico; lo que pasa es que no exhiben consistencia dentro de las explicaciones que dan los positivistas.

La teoría de la Regla de Reconocimiento también ha sido atacada por su circularidad: RR se identifica por la práctica de los oficiales; los oficiales se identifican por las normas secundarias que confieren poderes y éstas, a su vez por la Regla de Reconocimiento. Ciertamente, puede aceptarse como lo recuerdan Atienza y Ruiz Manero, que la circularidad es inevitable en todo sistema autoreferente ${ }^{92}$ (la construcción y diferenciación de componentes es mutuamente interdependiente). Lo que resulta menos claro es cómo, en esas condiciones, puede RR constituir una verdadera regla de "reconocimiento". En todo caso habría que entender que sería una regla de reconocimiento a posteriori, dado que la identificacion de las normas válidas la hace después y de acuerdo con los criterios que seleccionen los operadores. A ratos parece que Hart y sus seguidores piensan el proceso como si los jueces, al momento de decidir, no partiesen directamente de las normas aplicables al caso, sino que harían algo como verificar primero "qué es lo qué dice la regla de reconocimiento", después de lo cual recién procederían a seleccionar las normas válidas a aplicar de acuerdo con los criterios que RR conceda ${ }^{93}$. Quizás esto no sea exactamente lo que ocurre en la práctica. Cuando los jueces deciden, parten de identificar las normas concretas relevantes para el caso, y si no existen las crean, sin que sientan la necesidad de investigar qué es lo que permite, o no, una tal Regla de Reconocimiento. Salvo que por ésta se entienda concretamente a una Constitución, o un artículo constitucional que estipula las fuentes jurídicas vinculantes. Pero en tal supuesto, la noción de regla de reconocimiento resultaría perfectamente prescindible ${ }^{94}$.

${ }^{92}$ Cfr. M. Atienza, J. Ruiz M., Theory of Legal Sentences, Kluwer Academic Publishers, Netherlands, 1998, p. 81).

${ }^{93}$ H. Hart, The Concept of Law, p. 100 "decir que una determinada regla es válida es reconocer que supera todas las pruebas establecidas por la regla de reconocimiento, ypor tanto como una regla del sistema. Podemos decir sencillamente que el enunciado de que una regla concreta es válida significa que satisface todos los criterios establecidos por la regla de reconocimiento", en Robles, p. 398).

${ }^{94}$ En el mismo sentido Gregorio Robles, Hart: Algunos Puntos Críticos, en DOXA, No. 21-II, Alicante, 1998, edición virtual, p. 398, quién considera que la teoría de la regla de reconocimiento es un pesado "yugo" de la norma fundamental kelseniana, de la que Hart no 
El contenido mínimo de derecho natural

El cuarto dardo hartiano contra la tesis de la separación proviene del llamado contenido mínimo de derecho natural y la regla de la justicia formal. En este caso se trata de un conflicto abierto, desde que Hart acepta expresamente que, a nivel del derecho como sistema, ha de haber algún tipo de conexión "necesaria" entre derecho y moral. "La conexión entre derecho y estándares morales y principios de justicia -escribe-es por tanto tan poco arbitraria y tan "necesaria" como la conexión entre derecho y sanción, y responder a la cuestión de si esta necesidad es lógica (parte del "significado" del derecho) o simplemente factual o causal, puede ser dejada como un inocente pasatiempo de los filósofos"95. En otro lado, reconoce también que en la administración del derecho es inevitable proceder de acuerdo con la regla de justicia formal (tratar igual los casos iguales) ${ }^{96}$.

Esa vinculación derecho-moral vendría dada por un "contenido mínimo de derecho natural”, cuyo contenido valorativo Hart quiere atenuar al tratar de identificarlo con un conjunto de características utilitarias que se desprenden de las necesidades de supervivencia. Sin embargo, autores como Urbina han observado que resulta difícil evitar que esas características de la supervivencia "natural" puedan derivar en criterios morales ${ }^{97}$.

\section{Falacias}

Una de las primeras falacias (sustantiva en este caso) en las que incurre el positivismo es pretender que se puede dar una imagen puramente descriptiva del derecho, sin comprometer el punto de vista del observador; sin aceptar que "describir", con particular fuerza en materia social, es en alguna medida, "constituir" algo. Las teorías jurídicas no sólo describen sino que, de algún modo, proponen, performan la construcción del derecho. Ésta es una crítica que alcanza, en general a todo el positivismo como escuela epistemológica, y forma parte de los clásicos argumentos esgrimidos contra el positivismo por corrientes como la teoría crítica, el racionalismo crítico, y

\footnotetext{
logra desprenderse. Y ello parece ser así desde que Hart dice que "Kelsen y muchos teóricos modernos insisten en que,como a nivel estatal, el derecho internacional posee y de hecho debe poseer una "norma básica", o lo que nosotros hemos llamado una regla de reconocimiento (sic), en referencia a la cual, la validez de las otras reglas del sistema es evaluada", H. Hart. The Concept of Law, ed.cit. p. 233.

${ }^{95}$ H. Hart, Postivism and The Separation of Law and Morals, loc. cit. p. 622.

${ }^{96}$ Idem, p. 624.

${ }^{97}$ Sebastián Urbina, op. cit. pp. 48, 49. Recordemos también, a propósito, que ahora se toma más en serio la idea de que los derechos se desprenden, finalmente de las necesidades. Cfr. Ruth Zimmerling, Necesidades Básicas y Relativismo Moral, en El Concepto de Influencia y Otros Ensayos, Fontamara S.A., México D.F., 1993, pp. 67 y ss.
} 
el realismo científico ${ }^{98}$. Un punto de vista coincidente es acuñado por Urbina cuando indica que "no hay descripciones neutrales sino selectivas, que evalúan como "adecuado" o "relevante" ciertos elementos o vistas para una "propia” descripción" 99.

De tal manera que la posibilidad de que un observador externo pueda ofrecer una imagen plena del derecho, sin ser afectado ni afectar los juegos semánticos de los participantes, es extraordinariamente rara.

Además es poco convincente que una descripción de lo social sea completa, si quién describe no se ubica dentro de los significados que los actores sociales comparten. Como ha escrito Finnis, entre otros:

“... el desarrollo de la jurisprudencia moderna sugiere, y las reflexiones sobre la metodología de cualquier ciencia social confirman, que un teórico no puede dar una descripción teórica y un análisis de los hechos sociales, a menos que él participe en el trabajo de evaluación, de comprensión de lo que es realmente bueno para los seres humanos, y de lo que es realmente requerido por la razonabilidad práctica”. ${ }^{100}$

Un observador externo que no está dentro de la comunidad, y que no ve las razones sustantivas por las cuáles los participantes aceptan el derecho, en realidad no ve todavía gran cosa. Si se queda allí, diríamos que es un mal observador. De esto ya se previene Hart cuando sugiere que la investigación del observador puede variar "después de un tiempo"101. Pero en lugar de señalar que el proceso de aproximación al hecho jurídico, puede avanzar desde quién en el comienzo sólo ve movimientos exteriores (conductas y códigos escritos), hasta quién logra ubicarse y comprender la semántica de los participantes (punto de vista interno), Hart postula que ambos son dos puntos de vista distintos e igualmente legítimos para entender el Derecho. Además, cree que es más conveniente definir a éste desde el punto de vista del "observador" externo, que es justamente quién todavía no logra "ver" todo del fenómeno.

El observador externo de Hart que contempla el orden jurídico "sin aceptar las razones de los participantes", en realidad no es alguien que "no acepta", sino alguien que no "ve" las razones sustantivas que los participan-

${ }^{98}$ Vid. Norman Stockman, Antipositivist Theories of the Sciences, D. Reidel Publishing Company, Netherlands, 1983.

${ }^{99}$ S. Urbina, op. cit. p. 39.

100 "... the development of modern jurisprudence suggests, and reflections on the methodology of any social science confirmns, that a theorist cannot give a theoretical despcription and analysis of social facts, unless he also participates in the work of evaluation, of understanding what is realyy good for human persons, and what is really required by practical reasobleness", John Finnis, Natural Law and Natural Rights, Clarendon Press Oxford, 1980, p. 3.

${ }^{101}$ H. Hart, The concept of Law, ed.cit, p. 889. 
tes $-\mathrm{y}$ en especial los jueces - tienen en cuenta para considerar algo como Derecho. Por otra parte, al suponer que puede definirse el Derecho con independencia del contenido aceptado por los participantes, Hart está implicitando (normativamente) la posibilidad de contenidos jurídicos injustos, autocráticos, o incluso contrarios a las preferencias de la gente. Una postura que difícilmente puede considerarse valorativamente neutral, sino, en todo caso, valorativamente perversa. Si ello es así, la conclusión inevitable que se sigue es que la distinción hartiana entre punto de vista interno y punto de vista externo es equívoca, o cuando menos artificiosa, o cuando menos superflua ${ }^{102}$.

La segunda falacia del positivismo es la que llamaremos "falacia analítica". Aquí interesa destacar un conjunto de problemas de non sequitur que concurren, a nuestro juicio, tanto por el lado de Kelsen, como por el de Austin-Hart.

Cuando Kelsen dice que el propósito de su teoría es "conocer y describir su objeto", debería entenderse que su descripción es "avalorada”, en el sentido de que el investigador no toma partido ni a favor ni en contra, de lo que encuentra. Sin embargo lo que Kelsen implica, como ya se ha advertido antes, es que el investigador de antemano no se propone describir los valores que pudieran estar, o no, imbricados en su objeto. El positivismo de Kelsen confunde la meta de una descripción "avalorada" con la conclusión anticipada de que el derecho no tiene valores. De la misma manera que Hart, cuando dice que el observador externo observa "sin aceptar", lo que implica en verdad no es que el observador "no acepta", sino que el observador "no toma en cuenta", o "no describe" los valores. Porque, sin duda, se pueden describir los valores que una comunidad postula, aun cuando no se muestre interés explícito a favor o en contra de ellos. Hart parece confundir el "no compartir" con el "no describir", lo que claramente son cosas distintas. Un positivismo que quisiera ser consecuente con una motivación científica desinteresada, no debería tener problemas para avanzar a una descripción de las valoraciones que se implican en el derecho, cualesquiera éstas sean, cuán relativas sean éstas, o cuán difícil sea este trabajo; aunque en el final, el investigador pudiera o no emitir un juicio de valor sobre los valores que encuentre.

Tampoco se puede decir algo como: "puesto que los valores no se pueden describir de un modo universalista (incluso suponiendo que así sea, como se asume desde el relativismo kelseniano), no los incluyo en mi definición". En un caso extremo como éste, se podría decir también: “derecho son normas

${ }^{102}$ En sentido semejante, Gregorio Robles, Hart: Algunos Puntos Críticos, en DOXA N ${ }^{\circ}$ 21-II, Alicante, 1998, edición virtual, p. 397. 
de comportamiento que los participantes aceptan como obligatorias porque creen ligadas a diversos contenidos que llaman justos, o que imaginan morales, o que sienten buenos" etc. Incluso desde un relativismo absoluto, no es válido concluir que derecho sea algo que no tiene contenido, o que no tiene valor, o cuyo valor es indiferente para los participantes.

Una falacia semejante proviene de pasar de la afirmación de que el derecho es posible como ciencia con objeto propio (Kelsen y Hart), a la conclusión subrepticia de que ese objeto no tendría referente sustantivo alguno. El que el derecho tenga objeto propio, no quiere decir de por sí que ese objeto esté exento de valoraciones incluidas. Justamente la discusión que se da entre positivistas y iusnaturalistas no ocurre porque estos últimos nieguen que el derecho pueda tener objeto propio, sino porque se alega por ellos que el objeto debería abarcar también algunos componentes sustantivos.

Mirado con cierto detenimiento, el dogma fundamental austiniano de la separación entre "existencia" y "mérito" se revela también como una falacia de carácter analítica: del hecho que existencia y mérito son analíticamente diferenciables, Austin concluye que se dan por separado. Resulta algo así como decir "la manzana es una cosa y su sabor es otra; por lo tanto la manzana existe separada de su sabor: usted se queda con el sabor y yo me quedo con la manzana”. Lo que Austin ni sus comentaristas posteriores advierten, es que el mérito se da justamente en la existencia. Toda existencia tiene algún tipo de mérito, y como tal, nada obsta para que el mérito pueda también formar parte de la definición.

En otros casos de la idea de que moral y derecho pueden ser diferenciables parecen derivar rápidamente a la conclusión de que esa diferencia se da en el contenido. Pero ¿por qué no podría darse sólo en la forma? Teóricamente es admisible que aunque derecho y moral sean separables, esa diferencia podría no ser en el contenido, o cuando menos no en ciertos contenidos mínimos; sino digamos sólo en la forma, en la compulsoriedad, en el hecho de estar escrito, en el hecho de estar institucionalizado, en la forma de producción, etc. La separación positivista contradice intuiciones básicas. Es altamente probable que ningún hombre común aceptaría la idea de que pueda haber alguna diferencia de contenido radical entre derecho y moral.

Por otro lado (Austin nuevamente, y trás de él Hart), de la circunstancia de que en teoría puede diferenciarse entre el derecho que "es" y el que "debe ser", concluyen asociando el derecho con lo que "es", y la moral con lo que "debe ser". Sin embargo, en teoría nada impide que el derecho y la moral se encuentren unidos tanto en el "ser" como en el "deber ser". Puede haber moral en el derecho de hoy, como en el que quisiéramos para mañana. Y sin embargo aun así sería posible mantener alguna diferencia entre el derecho que "es" (conectado a cierta moral, positiva por ejemplo), y el derecho que 
"debe ser" (conectado a una moral crítica en este caso). Entonces no se trataría de una separación absoluta entre "ser-derecho" y "deber ser-moral", sino de la posibilidad de comparar en el tiempo contenidos jurídicos con diferentes grados de moralidad.

\section{Perversiones}

Hablemos ahora un poco de algunas de las consecuencias de las teorías de los autores sumariamente revisados. Cualquiera de ellos, y desde luego cualquiera de sus seguidores, estarían siempre dispuestos a sostener que positivismo no equivale a formalismo ni a legalismo. Este descargo (justificado) lo hace, como sabemos, Hart, defendiendo de paso a Bentham y Austin. Y tal parece que del formalismo pueden todavía escapar, porque es cierto que ni Austin, ni Kelsen, ni Hart defienden expresamente en algún lado que las decisiones jurídicas puedan surgir por mera consecuencia lógica o literal. A consecuencia parece injusto también que deban ser recusados de legalistas, cuando además, aceptan que la creación del Derecho proviene también de fuentes como la costumbre y las decisiones judiciales. No obstante hay razones para pensar que no pueden exculparse -cuando menos no totalmente- de ello. No sólo por lo que han hecho ciertos positivistas en la práctica, sino por lo que está implícito en la propia exposición de las teorías de los autores clásicos.

Ya antes se anotó que cuando Austin asume la frase de Bentham de que "ningún derecho positivo es injusto", se revela como un "positivista ideológico" sincero. En Kelsen, por otra parte, el legalismo puede tener algún vínculo con la tesis de la norma fundamental que expresa la obligación de seguir la Constitución ${ }^{103}$, sin interesarse por la legitimidad de sus fuentes de origen. Kelsen no distingue entre Constituciones obedecibles y no obedecibles, porque parece asumir que el origen de la primera Constitución no es relevante para la validez del derecho. $\mathrm{Y}$ en Kelsen es perfectamente claro que ninguna norma es válida, y ninguna autoridad es legal, si no está afirmada en otra norma previa, preexistente. La posibilidad de que de ahí se derive a considerar que toda decisión jurídica tenga que fundarse en una norma legal preestablecida es, en esas condiciones, poco menos que difícil. Y este paso lo dan sin mayor dificultad los prácticos del derecho que no necesitan indagar con mayor profundidad en las "oscuridades" de la teoría kelseniana para concluir que

103 "Therefore this norm, namely the basic norm of the legal order concerned, must be formulated as follows: Coercive acts sought to be performed under the conditions and in the manner which the historically first constitution, and the norms created according to it, prescribe. (In short: one ought to behave as the constitution prescribes", H. Kelsen, Pure Theory of Law, ed. cit. pp. 200-201. 
toda norma válida tiene que estar previamente escrita para poder usarse. Los aspectos de voluntarismo y decisionismo son casi olvidados en los seguidores de Kelsen, a nuestro juicio porque están desconectados del tronco principal de la teoría kelseniana u ocupan un lugar secundario en ella.

Hart tampoco defiende legalismo alguno, pero ello puede estar implícito en afirmaciones como ésta, que el autor inglés anota reseñando -por alguna razón- el punto de vista de Austin y Bentham:

"Lo que Bentham y Austin estuvieron ansiosos de afirmar eran las siguientes dos simples cosas: primero, en ausencia de una disposición constitucional expresa o provisión legal (énfasis añadido), no puede seguirse del mero hecho que una regla viola estándares de moralidad que esta no fuera una regla de derecho; e inversamente (léase: en ausencia de una disposición constitucional expresa o provisión legal), no podría seguirse del mero hecho que una regla fuera moralmente deseable que esta fuera una regla de derecho" ${ }^{104}$. Es decir, en ausencia de una disposición constitucional expresa o provisión legal, ningún contenido es, o no es, derecho. Puesto en afirmativo: el derecho es lo que dicen la Constitución y las provisiones legales.

En Hart, la posibilidad de pasar a un legalismo queda también abierta por el lado de la Regla de Reconocimiento, si por ejemplo estamos ante una comunidad de oficiales y ciudadanos que reconocen el derecho por estar previsto únicamente en las leyes. Hart no descarta esa posibilidad a juzgar por algunas de sus expresiones: "en un sistema legal moderno-dice-donde hay una variedad de 'fuentes' del derecho, la regla de reconocimiento es correspondientemente más compleja: los criterios para identificar el derecho son múltiples y comúnmente incluyen una constitución escrita, disposiciones legislativas y precedentes judiciales. En la mayoría de casos, se establecen provisiones para posibles conflictos, jerarquizando esos criterios en un orden de subordinación relativa y primacía. Es en esta forma que nuestro sistema de 'common law' es subordinado a las leyes (Estatutes)"'105.

Empero, lo que resulta más probable es que, en la práctica, el legalismo surja de una combinación perniciosa de al menos tres ideas positivistas, en coalición con la tesis política de la separación fuerte entre funciones legislativas y judiciales: por un lado de la insistencia de que la moral de por sí no es derecho (Kelsen y Hart); por otro lado, de la idea de que sólo son aplicables

${ }^{104}$ H. Hart, Positivism and The Separation of Law and Morals, loc. cit. p. 599.

105 "In a modern legal system where there are a variety of 'sources' of law, the rule of recognition is correspondingly more complex: the criteria for indentifying the law are multiple and commonly include a written constitution, enactment by legislature, and juditial precedents. In most cases, provision is made for possible conflict by ranking these criteria in an order of relative subordination and primacy. It is in this way that in our system 'common law'is subordinate to statute” H. Hart, The Concept of Law, ed.cit. p. 101. 
las normas válidas, y sólo son válidas las normas que se originan en otras normas (Kelsen); así como de los intentos por restringir la discreción judicial y concebirla sólo como discreción "intersticial” (Hart). De ese modo, si a un juez se le dicen estas cuatro cosas (que los argumentos morales en sí mismos no son derecho; que toda norma para ser aplicada tiene que respaldarse en alguna otra norma previa, que el juez no tiene sino discreción débil, y que además las funciones judiciales son diferentes a las del legislativo) le queda al operador, en la práctica, muy poco margen para no concluir en que: es derecho, lo que dicen las leyes escritas.

Sin embargo, a la par de negar cualquier ataque de legalismo, algunos positivistas podrían estar dispuestos a vincular positivismo con imperio de la ley ${ }^{106}$ y a consecuencia con la seguridad jurídica. Es probable que algunos autores puedan haber pensado, incluso, que sólo el positivismo -y no el iusnaturalismo, ni el realismo- constituirían garantía para el estado de derecho y la seguridad jurídica.

Enfrentados a esa suposición resulta oportuno preguntarse si la tesis del imperio de la ley, y consecuentemente del estado de derecho, corresponden a la matriz positivista, o son más bien herencia del liberalismo democrático y de otras tradiciones. Pensamos que esto último se ajusta mejor a la manera en que se han ido formando los valores de los estados democráticos contemporáneos. Lo que se trasunta en el positivismo es la asunción implícita de las conclusiones liberal democráticas, en particular la tesis de la separación de poderes y su consecuencia, la primacía de la ley; la que sin embargo deviene llevada a sus extremas y paradójicas consecuencias: se legitima el imperio de cualquier ley por el sólo hecho de ser "positivamente" existente.

El positivismo supone que ha de reconocerse como derecho incluso órdenes de reglas "inmorales" o "inicuas", algo que, como se recuerda, tanto Kelsen como Hart aceptan de manera expresa. En cambio para los pensadores liberal-democráticos, el respeto y la subordinación a la ley proviene del origen democrático de ésta. Aun en el extremo del dogma de Montesquieu, su presupuesto no es que el juez debe ser "boca" de cualquier ley, sino de aquélla que emana de la soberanía popular. Es decir imperio de la ley democrática (redundancia que tendría que ser innecesaria), sobre la base de reconocer cuando menos el principio democrático y los derechos humanos, como ha escrito también Francisco Laporta ${ }^{107}$.

${ }^{106}$ Considérese por ejemplo el intento de Raz de asociar el estado de derecho con una concepción "instrumental" (léase positivista) del derecho. En The Authority of Law, ed. cit. pp. 225-226.

${ }^{107}$ Vid, F. Laporta, Imperio de la Ley, en DOXA, № 15-16, Alicante, 1994 (edición virtual) p. 138 . 
El positivismo adopta - o coincide- con el punto de llegada de la tesis liberal democrático, pero lo sobrepasa y lo lleva a consecuencias ajenas, al desentenderse de los fundamentos democráticos y liberales que justifican y definen el estado de derecho. El imperio del derecho equivaldría al imperio de cualquier ley fácticamente existente, instrumental a cualquier poder, con independencia de sus propósitos y de la legitimidad de sus fuentes de origen. Como dice Raz, "Por cierto, conformidad al imperio de la ley (rule of law) también permite al derecho servir a malos propósitos" 108 .

Se completa así el círculo perverso: el liberalismo democrático inventó el sufragio y la separación de poderes; por tanto el estado de derecho; por tanto la autoridad de la ley. El positivismo viene a continuación y anida en estos presupuestos y extiende la autoridad de la ley, a cualquier ley y a cualquier estado, y por tanto a cualquier dictadura. El derecho no requiere estar vinculado a la moral o algún presupuesto razonable, para ser tal. Por tanto puede haber derecho malévolo. Por tanto, podría haber derecho incluso contra los supuestos éticos del liberalismo democrático.

Si esta interpretación es exacta, ella sugiere que, en rigor, el positivismo definido por sus tesis fundamentales, no constituye por sí mismo garantía de legalidad democrática ni menos de seguridad jurídica. Tanto la regla de reconocimiento hartiana, como la norma fundamental kelseniana aceptan como derecho cualquier voluntad normativa, con independencia de sus fuentes de legitimidad. Pensamos que las garantías del estado de derecho provienen de otros lados. Ante todo de la separación y control de poderes, y de la formación democrática (legítima) de las normas.

Ultimadamente, la seguridad jurídica no proviene tampoco directamente de la autoridad de la ley ni de su origen democrático, sino del principio de estabilidad constitucional. El legalismo positivista no opone de por sí ninguna valla teórica para que el derecho no pueda ser cambiado constantemente, cuando menos no en el nivel legislativo. Para eso se necesita de tesis como las de rigidez y estabilidad Constitucional, las cuales pensamos han sido propuestas con mejor coherencia desde la teoría del Derecho Constitucional.

${ }^{108}$ J. Raz, The Authority of Law, ed. cit. p. 225, y más adelante: “... la conformidad con el imperio del derecho (rule of law) es la virtud del derecho en sí mismo, el derecho como derecho sin considerar los propósitos a los que este sirve (énfasis añadido), ... Considerar el imperio del derecho como la especifica o inherente virtud del derecho es el resultado de un concepción instrumental del derecho..." 


\section{Enigmas}

Más allá de todas estas dificultades, creemos que el positivismo no da respuesta a otros problemas implícitos en la exposición de sus principales figuras.

¿La tesis de la separación moral/derecho acarrea que también hay separación derecho/política y derecho/economía? Kelsen, coherentemente, dice que sí. Sin embargo Hart admite que las policies o los "objetivos sociales” operan en la penumbra de las normas ${ }^{109}$. ¿Por qué esto sí es posible con las policies y no con los valores morales? Hart no es claro en reconocer que valores morales propios puedan también operar en la penumbra del derecho en la misma medida que las policies. Con ello presta, sin duda, servicio al utilitarismo; o quizás en el fondo desconfía que la moral pueda ser de algún modo fundamentable.

La pregunta contraria también es pertinente: ¿Por qué sí operar con la moral en los espacios de discreción y por qué no con las policies? Y a nuestro juicio no hay nada que impida que unos y otros criterios sustantivos puedan ser usados por los operadores, y que además puedan aportar a la definición de lo jurídico dentro de cierto umbral de razonabilidad.

También subsisten para el positivismo el problema de los fundamentos de la autoridad y del deber de obediencia del derecho. Ya se aludió a las dificultades de Hart para mantener la coherencia de las tesis del carácter normativo de las reglas. Hart admite -como lo hace Kelsen- que ha de haber alguna diferencia entre obedecer al derecho y obedecer a una banda de ladrones. Sin embargo no termina de aceptar que la obediencia al derecho, tanto por el lado de la gente, como por el de los oficiales, presupone inevitablemente lo que llama el "punto de vista interno". Kelsen, por su lado, a pesar de que defiende el carácter normativo de los "hechos" del derecho, parece identificar la autoridad y la obediencia con el poder coactivo de las normas: "La conducta mandada por un orden social es la que un individuo está obligado a adoptar...Decir "una conducta es mandada” es sinónimo de decir "un individuo tiene la obligación de comportarse en una cierta for$m a " 110$. Pero entonces ¿Puede establecerse alguna diferencia entre derecho y dominación?

El otro enigma de la teoría positivista tiene que ver con el razonamiento legal. Albert Calsamiglia ha señalado a este respecto, que el positivismo no tiene una teoría de la adjudicación ${ }^{111}$. Otros autores indican, en la misma

\footnotetext{
${ }^{109}$ Cfr. H. Hart. Positivism and the Separation of Law and Morals, loc. cit. p. 614.

${ }^{110}$ The behavior commanded by a social order is that which an individual is obligated to adopt... To say "a behavior is commanded" is synonymous whit saying "an individual has the obligation to behave in a certain way",", H. Kelsen, Pure Theory of Law, ed.cit, pp. 114-115.

${ }^{111}$ Vid. A. Calsamiglia, loc. cit., p. 212.
} 
dirección, que no tiene una teoría de la interpretación. Por nuestra cuenta hemos sostenido que esto es lo único que puede aspirar a tener: una teoría de la interpretación, entendida -sensu stricto- como una teoría de la explicitación de significados normativos pasados ${ }^{112}$. En cambio lo que no puede tener, por que no es epistemológicamente apto para ello ${ }^{113}$, es una teoría de la argumentación judicial y por tanto del razonamiento legal razonable. El estilo de razonamiento que algunos autores positivistas defienden, a veces como discreción débil, o como discreción fuerte, o a veces de tipo justificativo, es bienvenido pero se muestra contradictorio con los postulados fundacionales de su teoría.

Esto último lo advierte también, entre otros, MacCormick, cuando dice: “...tenemos que enfrentar un problema para el positivismo legal: si una teoría positivista simplemente da un recuento descriptivo de lo que los sistemas legales actualmente son, ¿cómo puede la versión positivista de la tesis de la 'validez' tener alguna referencia para la justificación?...una descripción positivista de los sistemas como estos operan no puede responder a una cuestión particular que puede ser planteada internamente en un sistema legal: la cuestión tal como puede plantearse por un juez en un caso difícil: 'Por qué debemos tratar cada decisión en concordancia con una regla válida, de acuerdo con nuestros criterios de validez, como si fuese suficientemente justificada" 114 .

La teoría positivista no proporciona un criterio claro para pasar de la descripción del derecho a su justificación. Este problema puede plantearse de otro modo: si se acepta que una cosa es el derecho que "es" y otra el que "debe ser": ¿con qué criterio deberían actuar los Jueces? De acuerdo con Montesquieu, con el derecho que "es". De acuerdo con las teorías del razonamiento legal racional: con el derecho que sea más razonable. ¿Y de acuerdo con los positivistas? Se tendrían, creemos, dos opciones básicas:

Que los operadores actúen sobre la base del derecho que "es" (de lo que RR autoriza). Esto quiere decir que, en principio, la separación conceptual

${ }^{112}$ Vid. L. Sánchez, Argumentación Jurídica e Interpretación, en Argumentación Jurídica y Teoría del Derecho, Ediciones el Alva, Arequipa, 1999.

${ }^{113}$ Vid. L. Sánchez, ¿Tiene el Positivismo Aptitud para Operar con Valores?, en Argumentación Jurídica y Teoría de Derecho, Ediciones, ed. cit.

114 “... we have to face a problem for legal positivism: if a positivist theory merely gives a descriptive account of what legal systems actually are, how can the positivist's version of the 'validity' thesis have any reference to 'justification'... "... a positivistic description of the system as it operates cannot answer a particular kind of question which may be raised internally to a legal system: the question as it might be raised for a judge in a hard case: 'Why ought we to treat every decision in accordance with a rule valid by our criteria of validity as being susufficiently justified?” . N. MacCormick, Legal Reasoning and Legal Theory, ed. cit. pp. 62 y 63. 
derecho-moral tendría fuerza vinculante. La discreción judicial se daría sólo en el marco del derecho reconocido por la Regla de Reconocimiento. Ahora, si RR reconoce sólo derecho formal sin posibilidad de remisión a criterio moral alguno, la separación es estricta y se conserva la coherencia positivista. Si RR reconoce la posibilidad de recurrir a ciertos criterios morales implícitos en el ordenamiento, entonces la discreción judicial se amplía, pero con la consecuencia de que pierde solidez la tesis de la separación. Si RR reconoce que puede usarse cualquier criterio moral, no sólo los contenidos en las normas preexistentes, la discreción es plena, pero la tesis de la separación pierde utilidad. En tal caso el dogma positivista básico tendría que rezar no que el derecho es conceptualmente diferente de la moral, sino algo como "el derecho puede ser separado o no, conceptualmente diferente o no, de la moral, dependiendo de lo que permita RR".

La otra posibilidad es reconocer que los jueces pueden decidir sobre la base del derecho que "debe ser", o indistintamente (lo que produce el mismo resultado) sobre la base del derecho que "es" y del que "debe ser". En ese caso la discreción judicial es plena: los jueces pueden decidir moralmente qué derecho aplicar; pueden recurrir a valoraciones y de ese modo pueden constituir derecho: el derecho es lo que los jueces dicen moralmente que es derecho. Por lo tanto, la tesis de la separación pierde toda significación.

En la práctica esto último puede que sea lo que ocurre. Los jueces deciden valorativamente, creativamente, incluso moralmente, a pesar del dogma positivista. Sin embargo cuando los jueces hacen eso no están legislando. En esto Hart tiene sin duda acierta, pero quizás la razón no resida en el hecho que el Juez no sale de las "líneas" que demarcan la penumbra; sino en admitir que la emisión de una decisión particular creativa, como lo entendía Kelsen, no equivale a legislar.

Comoquiera que sea, no parece que los diversos positivismos ofrezcan una respuesta consistente para esto.

Bribie Island, Australia, 10 de marzo del 2002

\section{Publicaciones anteriores:}

Argumentación Jurídica y Teoría del Derecho, La Crítica Actual del Positivismo Jurídico,Universidad Nacional de San Agustín, Editora el Alva, 220 pp. Arequipa. 1999.

Argumentación Jurídica y Teoría del Derecho, Rev. IUS ET PRAXIS, Universidad de Lima, 1999.

Límites del Modelo de Ciencia Jurídica Actual, ISONOMIA, No. 8, México D.F, 1998. 
Mercado y Justicia en el Derecho, en Revista DERECHO Y SOCIEDAD, Año VIII, No. 12, Nov. 1997, Pontificia Universidad Católica del Perú.

Argumentación Jurídica e Interpretación Constitucional, en Rev. SCRIBAS No. 3, Arequipa, 1997. 
$\triangle \quad$ DOXA 25 (2002) 